\title{
ANALISIS SENTIMEN PADA PEMERINTAHAN TERPILIH PADA PILPRES 2019 DITWITTER MENGGUNAKAN ALGORITME NAÏVEBAYES
}

\author{
Febby Apri Wenando ${ }^{1 *}$, Regiolina Hayami ${ }^{1}$, Agung Jefrianto Anggrawan ${ }^{1}$ \\ ${ }^{1}$ Teknik Informatika, Universitas Muhammadiyah Riau \\ email: *febbyapri@umri.ac.id
}

\begin{abstract}
The Presidential general election on 2019 became one of the most popular topics on twitter nowdays. The society give their opinion about the pair of candidates that they are support through the social media. This research was predicts about the society sentimens toward the candidates of President and Vice President of Republic of Indonesia. The data was used based on the tweet on the @ jokowi twitter account. The retrieval of data by using the Tweepy library with the Python 2.7 programming language. This research was classified became of two of society sentiments classes, namely positive and negative. The modeling was used of the weighting method Unigram, Bigram, Trigram, N-Gram (1-2) and N-Gram (1-3) that used the Naïve Bayes Algorithm on the Weka Application. The modeling data was used by the dataset of 646 sentences. The highest results of this reseach were obtained by Unigram Weighting, namely: $81.4 \%$ accuracy, $81.5 \%$ precision, $81.3 \%$ recall with a time of $0.3 \mathrm{~s}$.
\end{abstract}

Keywords: classification, naïve bayes, 2019 presidential election, twitter, unigram

Abstrak: Pemilihan Umum tentang Pilpres 2019 menjadi salah satu topik yang ramai diperbincangkan di Twitter. Adu pendapat di sosial media oleh masyarakat mengandung opini terhadap pasangan calon yang didukungnya. Penelitian ini memprediksi sentimen masyarakat kepada pasangan calon Presiden dan Wakil Presiden Republik Indonesia. Data yang digunakan adalah tweet yang ada pada akun Twitter @jokowi. Pengambilan data menggunakan library Tweepy dengan bahasa pemrograman Python 2.7. Penelitian ini mengklasifikasi sentimen masyarakat menjadi 2 kelas, yaitu positif dan negatif. Kemudian dilakukan pemodelan dengan metode pembobotan Unigram, Bigram, Trigram, N-Gram (1-2) Dan N-Gram (1-3) menggunakan Algoritme Naïve Bayes pada Aplikasi Weka. Pembuatan model menggunakan dataset yang berjumlah 646 kalimat. Hasil tertinggi yang diperoleh pada penelitian ini adalah dengan menggunakan Pembobotan Unigram, yaitu : akurasi 81,4\%, presisi 81,5\%, recall 81,3\% dengan catatan waktu $0,3 \mathrm{~s}$.

Kata kunci: klasifikasi, naïve bayes, pilpres 2019, twitter, unigram.

\section{PENDAHULUAN}

Indonesia merupakan negara yang menganut sistem demokrasi. Hal tersebut dibuktikan dengan diada-kannya pemilihan umum dalam pemerintah baik pusat maupun daerah. Pemilu diselenggarakan dalam 5 tahun sekali. Perbincangan terkait Pemilu ini menjadi hangat diakalangan masya-rakat, berbagai pikiran dan padangan politik dalam PILPRES baik yang pro maupun kontra sudah semakin banyak bermunculan, misalnya munculnya hastag \#gantipresiden dan lain sebagainya.

Twitter termasuk media sosial yang ramai digunakan masyarakat saat ini untuk saling berbagi dan bertukar 
informasi. Saat ini Twitter banyak digunakan untuk berbagai kepentingan, seperti media sosial untuk membangun pertemanan dalam skala luas dan untuk saling bertukar fikiran dan menyampaikan pendapat. Selain itu, Twitter juga dapat digunakan untuk alat promosi dan kampanye dalam hal kepentingan politik. Data di media sosial twitter yang berupa teks, maka data ini dapat di olah menjadi sebuah informasi dan pengetahuan yang berguna terhadap isu yang berkembang[1].

Text mining merupakan teknik penambangan data teks yang bertujuan untuk mendapatkan kembali informasi yang ada pada data teks, yang diekstrak secara otomatis dari sumber-sumber data teks yang digunakan sebagai dataset[1] [2]. Pada penelitian terkait analisis sentimen, digunakan dataset dari pendapat atau opini masyarakat[3].

Selanjutnya pendapat/ opini masyarakat tersebut dibagi menjadi 5(lima) kelas. Untuk dapat meng-hasilkan suatu klasifikasi, penelitian ini menggunakan salahsatu jenis metode klasifikasi yaitu Nä̈ve Bayes Classifier(NBC). Dataset yang digunakana adalah data teks bahasa Indonesia berupa tweet dari Twitter tentang Calon Presiden Indonesia tahun 2014. Hasil yang diperoleh dari penggunaan 900 dataset pada penelitian tersebut yaitu nilai akurasi sebesar 71,9\%, nilai presisi sebesar $71,6 \%$, dan nilai recall sebesar $71,9 \%$. Sebuah model dibangun untuk melakukan analisis pada Pemilihan Gubernur dan Wakil Gubernur DKI Jakarta tahun 2017 [4] untuk mengetahui sentimen masyarakat di Twitter terhadap pasangan calon Gubernur dan Wakil Gubernur. Data yang digunakan diperoleh dengan menggunakan kata kunci(keyword) @ AhokDjarot dan @JktMajubersama. Hasil penelitian tersebut adalah prediksi data uji menggunakan algoritme Nä̈ve Bayes, dengan tingkat akurasi mencapai $60,60 \%$.

\section{METODE}

Tahapan dalam menyelesaikan penelitian ini dapat dilihat pada Gambar 1.

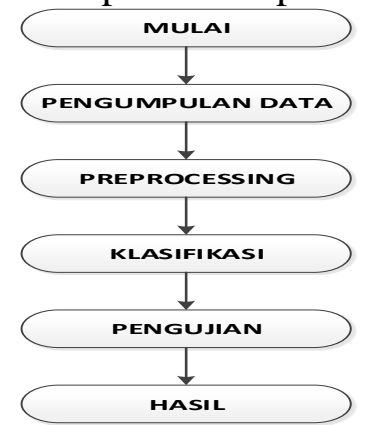

\section{Gambar 1 Metodologi Penelitian}

\section{Pengumpulan Data}

Penelitian ini menggunakan dataset Sentimen masyarakat PILPRES yang akan diambil dari data berisi tweet yang telah dianotasikan untuk PILPRES, khususnya dalam kategori pro dan kontra pada akun @jokowi. Kemudian data dibagi menjadi 2 kelas yaitu kelas positif dan kelas negatif.

\section{Preprocessing}

Preprocessing (pra-proses) pada penelitian ini bertujuan untuk menghapus data-data tweet error pada saat pengambilan data dan menyeleksi fitur berupa kata-kata atau term. Praproses penelitian ini menggunakan aplikasi Python ver. 2.7. Tahapan preprocessing, terdiri dari proses pembersihan karakter[4], stemming [5] dan stopword[6].

\section{Klasifikasi}

Data teks yang telah dilakukan pembersihan pada tahap preprocesing. Data teks tersebut akan diberikan bobot 
menggunakan Metode Pembobotan Kata TF-IDF N-Gram (1-2) dan N-Gram (1-3) yang bertujuan untuk mempresentasikan seberapa besar pengaruh bobot tersebut pada suatu dokumen[7]. Cara kerja pembobotan kata pada metode TF-IDF yaitu dengan menggunakan 2 parameter pembo-botan yaitu pembobotan lokal tfi.j adalah bobot yang didapat dari frekuensi kemunculan kata $i$ dalam dukumen $j$ dan pembobotan global dengan menggunakan idfi adalah bobot yang didapat dengan memper-timbangkan jumlah kemunculan kata $i(\mathrm{DF} i$ ) pada keseluruhan dukumen $\mathrm{N}$. Dan selanjutnya, nilai dari bobot lokal dikalikan dengan nilai dari bobot global maka didapat[8]. Cara menghitung bobotnya dengan persamaan(1) [7]:

$$
w_{i, j}=t f_{i, j} x\left(\log \left(\frac{N}{D F_{i}}\right)\right)
$$

Setelah

dataset

kemudian dilakukan klasifikasi menggunakan algoritme Nä̈ve Bayes[1]. Algoritme Naïve Bayes menggunakan pendekatan Bayes dalam melakukan proses klasisfikasi. Untuk mencari nilai probabalitias/ peluang tertinggi (Vmap) digunakan rumus(2) berikut: [8]

$V m a p=\arg P(V j \mid a 1, a 2, a 3, \ldots, a n)$

Keterangan:

Vmap $=$ Probabilitas/ peluang tertinggi a1, a2, a3, .., an =atribut data masukan

Persamaan diatas dapat ditulis menjadi rumus (3): [8]

$V$ map $=\arg \max \frac{p(a 1, a 2, a 3, \ldots, a n \mid V j) \mid p(V j)}{p(a 1, a 2, a 3, \ldots, a n)}$

Keterangan:

Vmap $=$ Probabilitas

$\mathrm{P}(\mathrm{Vj})=$ Probabilitas kelas ke $j$

$\mathrm{P}(\mathrm{a} 1, \mathrm{a} 2, \ldots, \mathrm{an})=$ Probabilitas atribut input $\mathrm{P}(\mathrm{a} 1, \mathrm{a} 2, . ., \mathrm{an} \mid \mathrm{Vj}) \quad=$ Probabilitas atribut input jika diketahui keadaan $\mathrm{V} j$ ke $j$

Pada penelitian yang dilakukan, pengolahan dataset menggunakan algoritme Nä̈ve Bayes akan diimple- mentasikan pada suatu sistem data mining yang disebut WEKA. Sistem ini berisikan tools yang mengimplementasikan algoritme data mining. WEKA digunakan untuk pra-pengolahan data (preprocessing), klasi-fikasi data, regresi, klasterisasi (clustering), aturan asosiasi dan visualisasi data[9].

\section{HASIL DAN PEMBAHASAN}

\section{Pengumpulan data}

Proses pengambilan data menggunakan Python 2.7, data yang digunakan adalah berupa teks berisikan sentimen masyarakat pada akun twitter @jokowi dengan format CSV yang berbentuk data tidak terstruktur[9], kemudian untuk mempermudah klasifikasi, peneliti memberikan label yang berfungsi untuk menyimpan nilai sentimen yang akan diklasifikasikan [10]. Data yang dikumpulkan dalam penelitian ini berjumlah 646 tweet, 476 teks yang bersifat positif dan 170 yang bersifat negatif. Dataset ini dikategorikan kepada unbalanced class.

\section{Preprocessing}

Preprocessing ini dilakukan dengan tiga tahap, yaitu:

1. Pembersihan karakter, yaitu menghilangkan karakter yang bisa mengurangi kualitas dataset yang akan dilatih. Seperti tanda hastag (\#), at (@) dan simbol karakter lainnya yang dianggap tidak perlu, seperti tercantum pada Tabel 1 .

2. Stemming adalah proses suatu kata menjadi kata dasar. Pada tahap ini akan dilakukan penghilangan semua imbuhan (affix) yang terdiri dari awalan (prefix), sisipan (infix), akhiran (suffix) dan duplikasi[6]. Tujuan dari proses ini adalah untuk 
mendapatkan kata dasar dari kata berimbuhan.

3. Stopword, adalah proses pembuangan kata-kata yang tidak memiliki arti atau tidak relevan. Katakata yang diperoleh dari tahap tokenisasi akan dicek pada daftar stopword, apabila sebuah kata tersebut masuk dalam daftar stopword maka kata tersebut akan dihilangkan dan tidak akan diproses lebih lanjut. Sebaliknya apabila sebuah kata tidak termasuk dalam daftar stopword maka kata tersebut akan masuk ke proses berikutnya.

Tabel 2 dan 3 merupakan contoh penerapan tahap 2 dan 3 dari preprocessing terhadap dataset.

\section{Klasifikasi}

Data bersih yang didapat setelah tahap preprocessing, kemudian dilakukan pemisahan tiap kata dengan menggunakan Aplikasi WEKA[9]. Pada proses klasifikasi data masukan yang digunakan adalah dokumen dengan tipe Atribut-Relation File Format(ARFF).
Hasil dari pemisahan tersebut selanjutnya dibobotkan dan diklasifikasi menggunakan algoritme Nä̈ve Bayes.

\section{Pengujian}

Pada tahapan pengujian hasil klasifikasi yang diperoleh selanjutya diuji. Pengujian hasil klasifikasi menggunakn teknik K-Fold Cross Validation, yaitu dengan jumlah percobaan (k) sebanyak 10 kali. Pengujian dilakukan dengan membagi dataset mejadi 10 bagian. Sebanyak 9(Sembilan) dari 10(sepuluh) bagian dataset digunakan untuk proses pelatihan(training). Sisanya digunakan untuk proses pengujian(testing). Iterasi atau perulangan terjadi sebanyak 10(sepuluh) kali dengan variasi kombinasi data sebanyak 10(sepuluh) bagian pada dataset untuk training maupun testing.

Tahapan pengujian dilakukan untuk menganalisa hasil dari pembelajaran mesin yang telah dilakukan, sehingga mendapatkan hasil akurasi, presisi, recall, dan waktu klasifikasi.

Tabel 1 Pembersihan Karakter

\begin{tabular}{clll}
\hline Label & \multicolumn{1}{c}{ Teks Awal } & \multicolumn{2}{c}{ Setelah Proses Pembersihan } \\
\hline Positif & RT @jokowi: telah berjuang untuk & RT jokowi telah berjuang untuk \\
& mengharumkan nama bangsa & mengharumkan nama bangsa \\
& Indonesia di mata dunia & Indonesia di mata dunia \\
Positif & RT @roninpribumi: Kata @jokowi & RT roninpribumi Kata jokowi \\
& demokrasi ada batasnya itu betul. & demokrasi ada batasnya itu betul \\
& Batasnya adalah HUKUM. Kalau & Batasnya adalah HUKUM Kalau \\
& tagar \#2019GantiPresiden dianggap & tagar GantiPresiden dianggap \\
& melanggar... & melanggar... \\
Negatif & RT @eae18: Saya bingung deh. Kan & RT eae Saya bingung deh Kan ada \\
& ada Yai Ma'ruf. Kan ada & Yai Maruf Kan ada imam nahrawi \\
& @imam_nahrawi Mosok Pak & Mosok Pak jokowi kutip hadis yang \\
& @jokowi kutip hadis yang salah & salah konteks didiamkan \\
& konteks didiamkan. & \\
\hline
\end{tabular}


DOI: https://doi.org/10.33330/jurteksi.v7i1.851

Available online at http://jurnal.stmikroyal.ac.id/index.php/jurteksi

\section{Tabel 2 Stemming}

\begin{tabular}{|c|c|c|}
\hline Label & Teks Awal & Setelah Proses Stemming \\
\hline Positif & $\begin{array}{l}\text { RT @jokowi: telah berjuang untuk } \\
\text { mengharumkan nama bangsa } \\
\text { Indonesia di mata dunia }\end{array}$ & $\begin{array}{l}\text { jokowi telah juang untuk harum } \\
\text { nama bangsa Indonesia di mata } \\
\text { dunia }\end{array}$ \\
\hline Positif & $\begin{array}{l}\text { RT @ @roninpribumi: Kata @jokowi } \\
\text { demokrasi ada batasnya itu betul. } \\
\text { Batasnya adalah HUKUM. Kalau tagar } \\
\text { \#2019GantiPresiden } \\
\text { melanggar... }\end{array}$ & $\begin{array}{l}\text { roninpribumi kata jokowi } \\
\text { demokrasi ada batas itu betul batas } \\
\text { adalah hukum kalau tagar } \\
\text { gantipresiden anggap langgar }\end{array}$ \\
\hline Negatif & $\begin{array}{l}\text { RT @eae18: Saya bingung deh. Kan } \\
\text { ada Yai Ma'ruf. Kan ada } \\
@ \text { imam_nahrawi Mosok Pak @jokowi } \\
\text { kutip hadis yang salah konteks } \\
\text { didiamkan. }\end{array}$ & $\begin{array}{l}\text { eae saya bingung deh kan ada yai } \\
\text { maruf kan ada imam nahrawi } \\
\text { mosok pak jokowi kutip hadis yang } \\
\text { salah konteks diam }\end{array}$ \\
\hline
\end{tabular}

Tabel 3 Stopword

\begin{tabular}{clll}
\hline Label & \multicolumn{1}{c}{ Teks Awal } & \multicolumn{2}{c}{ Setelah Proses Stopword } \\
\hline Positif & RT @jokowi: telah berjuang untuk & Jokowi berjuang harum nama \\
& mengharumkan nama bangsa & bangsa Indonesia mata dunia \\
& Indonesia di mata dunia & & \\
Positif & RT @ roninpribumi: Kata @jokowi roninpribumi kata jokowi \\
& demokrasi ada batasnya itu betul. & demokrasi batas betul batas hukum \\
& Batasnya adalah HUKUM. Kalau kalau tagar gantipresiden anggap \\
& tagar \#2019GantiPresiden dianggap & langgar... \\
& melanggar... \\
RT @eae18: Saya bingung deh. Kan & eae bingung deh kan yai ma ruf kan \\
& ada Yai Mairuf. Kan ada & imam nahrawi mosok pak jokowi \\
& @imam_nahrawi Mosok Pak kutip hadis salah konteks diam \\
& @jokowi kutip hadis yang salah \\
& konteks didiamkan.
\end{tabular}

\section{SIMPULAN}

Pada Klasifikasi ini peneliti menggunakan Algoritme Naive Bayes dengam pembobotan N-gram (1-2) dan Ngram(1-3). Hasilnya dapat dilihat pada tabel 4:

\begin{tabular}{lcc}
\multicolumn{3}{c}{ Tabel 4. Hasil Klasifikasi } \\
\hline Naïve Bayes & $\begin{array}{c}\text { N-gram } \\
(\mathbf{1 - 2})\end{array}$ & $\begin{array}{c}\text { N- } \\
\text { gram } \\
(\mathbf{1 - 3})\end{array}$ \\
\hline Accuracy (\%) & 80,5 & 80,2 \\
\hline Precision (\%) & 80,7 & 80,2 \\
\hline Recall (\%) & 80,3 & 80,2 \\
\hline Time (s) & 0,42 & 0,43 \\
\hline
\end{tabular}

Berdasarkan Tabel 4 dapat dilihat perbandingan persentase hasil akurasi(accuracy), presisi(precision), recall serta waktu(time). Dari hasil penggujian dapat dilihat bahwa algoritme Nä̈ve Bayes dengan TF-IDF berbasis NGram (1-2) menunjukkan hasil yang paling baik, dalam hal nilai akurasi(accuracy), presisi(precision), recall serta waktu(time) klasifikasi. Dengan nilai akurasi(accuracy) sebesar 80,5\%, presisi(precision) sebesar 80,7\%, recall sebesar $80,3 \%$ dengan catatan waktu(time) selama 0,42s. Namun, hasil 
tersebut tidak jauh berbeda dengan $\mathrm{N}$ Gram (1-3). Melalui penelitian ini juga diketahui bahwa Metode Pembobotan Kata N-Gram (1-2) dan (1-3) hasilnya sama baik dan tidak jauh berbeda ketika dilakukan.

\section{UCAPAN TERIMA KASIH}

Terima kasih kepada Kementerian Riset, Teknologi dan Pendidikan Tinggi(Kemenristek-Dikti) atas dukungan pendanaan dalam penelitian ini.

\section{DAFTAR PUSTAKA}

[1] \& S. J. Feldman, R, Text Minning Handbook: Advanced Approaches in Analyzing Unstructure Data. New York: Cambridge University Press., 2007.

[2] M. A. Razzaq, A. M. Qamar, and Hafiz Syed Muhammad Bilal, "Prediction and analysis of Pakistan election 2013 based on sentiment analysis," in 2014 IEEE/ACM International Conference on Advances in Social Networks Analysis and Mining (ASONAM 2014), Aug. 2014, pp. 700-703, doi: 10.1109/ASONAM.2014.6921662.

[3] G. A. Buntoro, T. B. Adji, and A. E. Purnamasari, "Sentiment Analysis Twitter dengan Kombinasi Lexion Based dan Double Propagation," CITEE, pp. 39-42, 2014.

[4] M. H. Rasyadi, "Analisis Sentimen Pada Twitter Menggunakan Metode Naïve Bayes(Studi Kasus Pemilihan Gubernur DKI Jakarta 2017),” 2017.

[5] F. Nausheen and S. H. Begum, "Sentiment analysis to predict election results using Python," in 2018 2nd International Conference on Inventive Systems and Control (ICISC), Jan. 2018, pp. 1259-1262, doi: 10.1109/ICISC.2018.8399007.

[6] F. . Tala, "A Study of Stemming Effects on Information Retrieval in Bahasa Indonesia," Inst. Log Lang. Comput. Univ. Van Amst. Neth., 2003.

[7] F. . Wenando, T. B. Adji, and Ardiyanto, "Text Classification to Detect Student Level of Understanding in Prior Knowledge Activation Process," Adv. Sci. Lett., vol. 23, no. 3, pp. 2285-2287, 2017.

[8] F. . Wenando and E. Fuad, "Detection of Hate Speech in Indonesian Language on Twitter Using Machine Learning Algorithm," Pros. CELSciTech, vol. 4, pp. 6-8, 2019.

[9] S. S. Aksenova, Mechine Learning with WEKA - WEKA Tutorial Explore Tutorial for WEKA Version 3.4.3. California, 2004.

[10] K. D. A, Normah, and U. A. H, "Prediction of Indonesia Presidential Election Results for the 2019-2024 Period Using Twitter Sentiment Analysis," 2019 5th Int. Conf. New Media Stud., pp. 36-42, 2019. 